\title{
Review of Grossman and Helpman's Special Interest Politics ${ }^{1}$
}

\author{
DAVID P. BARON ${ }^{2}$
}

\section{Introduction}

$I$ NTEREST GROUPS are ubiquitous in U.S. politics and in the political systems of most nations. In some countries, interest groups are closely aligned with political parties and exercise influence through those parties. In some countries, members represent their interest groups by holding offices in government. In the United States, interest groups typically are not identified with parties-although their members may predominately vote for one party-and do not represent their members directly in government. Instead, U.S. interest groups generally serve their members from outside government.

Expenditures on lobbying in the United States reported to the federal government totaled $\$ 1.45$ billion in 1999 , according to the Center for Responsive Politics (www.opensecrets.com). In addition, lobbying is conducted by many who are not required to report their activities and expenditures: individuals, business executives, labor leaders, and association members. Interest groups also make campaign contributions. In the year-2000 election cycle, political action committees (PACs) contributed $\$ 259.8$ mil-

${ }^{1}$ Special Interest Politics. By Gene M. Grossman and Elhanan Helpman. Cambridge and London: MIT Press, 2001. Pp. xv, 364. ISBN 0-262-07230-0.

${ }^{2}$ Stanford University Graduate School of Business. lion. Soft-money contributions by interest groups and individuals totaled nearly $\$ 500$ million. Both lobbying and election campaigns are amply funded by interest groups.

In Special Interest Politics, Gene Grossman and Elhanan Helpman study how special interest groups influence political outcomes to benefit their members. The title of the book is fitting, but understates the contribution of the authors. They take interest groups seriously by considering a range of theories and supporting evidence about interest-group activity. Their book, however, is much more than a thoughtful study of the political strategies of special interest groups (SIGs). It provides insights into how to study interest-group politics and provides a set of methods for that study. Although the authors present a number of standard models, they also present much that is new. The reader gains a multitude of results, tools, models, and new research ideas. The result is an outstanding book full of insight, useful methods, and perspective.

The book is intended for political economists and graduate students, as well as economists working in other fields who seek to add political forces to their work. The focus is positive throughout, although some of the analysis identifies Pareto improvements from political activities such as lobbying. The authors present "tools for analyzing the 
interaction between voters, interest groups, and politicians." They seek to "shed light on the mechanisms by which SIG activities affect policy outcomes" and to "portray the key tensions and conflicts" rather than explore how behavior varies with institutional details. The theory is made accessible to those outside the field through detailed discussions of the incentives facing interest groups and officeholders. The approach is theoretical but with an emphasis on intuition and understanding rather than on formalities and generality.

The focus on how and why SIGs have influence allows the authors to avoid the stumbling blocks that occupy the attention of many political scientists and political economists who study the behavior of public officeholders and candidates for those offices. For example, political economists who study electoral competition often work to escape the Downsian incentives that lead to the convergence of party positions. Grossman and Helpman focus instead on interestgroup influence. When there is convergence, they ask to what extent the convergent positions reflect the interests of SIGs-i.e., how the political strategies of the interest groups influence the common position.

The book is not oriented toward empirical applications or testing, but the models provide a wealth of falsifiable predictions. Testing predictions of models with private information can be a challenge, since the information of players is generally not observable. In many of the models analyzed by Grossman and Helpman, however, testing can focus on the relation between preferences and policies. For example, when some members of SIGs are imperfectly informed about the policies of parties, the parties cater to the preferences of the SIG with the greater number of better-informed members, and poorly informed voters are ignored. Consequently, those SIGs that expend resources informing and mobilizing their members should, other things equal, have more influence when there is uncertainty about party positions.

\section{Content, Organization, and Style}

Grossman and Helpman focus not on the magnitude of the effect of interest groups but instead on how they influence government policies. Influence can focus on government in office or on electing a government (Grossman and Helpman 1994). A complete theory would incorporate both arenas of influence, and the authors incorporate both in their theory. They accomplish this in two stages. First, they focus on a single officeholder and one activity such as informational lobbying or campaign contributions. In this stage reduced form preferences are used, for example, to represent subsequent electoral incentives. In the second stage they bring together information provision or campaign contributions with a formal model of elections.

The book is rigorously argued but the arguments are made without formal propositions and proofs. Equilibria are identified and their properties examined through careful analysis intended to help the reader understand the logic of equilibrium behavior. For example, to study costless lobbying, or cheap talk signaling, they begin with a twostate model, move to a three-state model, and then extend the logic to many states and a continuum. They also use a constructive approach for identifying equilibria. The typical approach is to begin with the basic incentives for the players, examine the interactions among their strategies, and verify that the strategies do or do not form an equilibrium. The players are assumed to be rational in the sense that they maximize an objective function, but they may be myopic or rationally ignorant. The approach throughout is game theoretic. For example, social choice theory is not used nor is Arrow's Impossibility Theorem mentioned.

In some political settings, institutional procedures determine the sequence of moves of 
players, as in the case of a legislative process. In many political settings, however, the sequence of moves is not specified, so there is little to guide the modeling of influence activities such as lobbying, endorsements, and campaign contributions. Grossman and Helpman are agnostic about the appropriate timing. For example, campaign contributions can be made before parties have chosen their policy positions or after the parties have committed to their positions, and the authors explore both. They use a set of baseline models that are carried throughout the book and are generalized to accommodate institutional features, alternative specifications of preferences, and different sequences of actions.

Empirical and anecdotal evidence identifies a variety of motives for influence activities. Campaign contributions can be made to obtain access to officeholders, affect the likelihood that a candidate is elected, or influence the policies chosen by parties and candidates. Again Grossman and Helpman consider all three motives. In addition, the strategic relationship between a contributor and a recipient can vary. A first-term member of Congress may have little bargaining power, whereas a senior member from a relatively safe district may have considerable bargaining power. Grossman and Helpman consider both, using a take-it-or-leave-it offer and a Nash bargaining model, respectively.

The book is organized in three parts: elections, lobbying, and campaign contributions. The authors provide an excellent overview in a long introductory chapter. The overview is worth reading both before the other parts and afterwards as a summary. The following sections highlight features of the three parts.

\section{Elections}

The positive orientation of the book leads to a focus on theories that have explanatory power. For example, most theories predict that turnout will be very low due to the cost of voting and the very small probability that a voter will be pivotal. William Riker and Peter Ordeshook (1968) explain turnout through a preference for voting, but this theory is not helpful in predicting which voters will turn out, since such preferences are not observable. Grossman and Helpman instead look for an explanation in social norms and ask which groups are best able to enforce a norm of voting. They argue that groups in which members have a stake in "interpersonal exchange" will best be able to enforce such a norm. This social connectedness can be strong, for example, among workers in the same industry or trade. This means that unions may be best able to enforce a norm of voting, and casual observation indicates that unions frequently conduct get-out-the-vote drives. This line of reasoning has a number of implications for policy choice based on who gets elected and how parties compete for interest groups' votes. Groups that are best able to enforce a norm of voting should be able to obtain policies that serve the interests of their members.

Grossman and Helpman take this perspective further by presenting a theory of electoral competition where two officeseeking parties compete in an election. With certain restrictions on preferences and a unidimensional policy space, both candidates locate at the ideal point of the median voter. To allow for distinct policies in an electoral equilibrium, they use a model in which parties have fixed positions on some policy issues and on other issues can choose pliable policies. The fixed policies allow for some difference between the parties, and in the absence of special interest groups (SIGs) the parties maximize the utility of the average voter. When the Downsian incentives lead to convergence of the pliable policies, those policies are not those preferred by strong partisans-those who vote primarily on the fixed positions of the parties-but instead reflect the interests of groups with many moderates who are roughly indifferent between the fixed positions of the parties. 
Strong partisans "will be largely ignored." Groups that have few partisans thus will have more influence on the pliable policies because the parties will compete for votes that can be attracted rather than those that cannot be influenced.

In a similar vein, suppose that some members of SIGs know the pliable policies of parties, whereas other members do not. Even though the Downsian incentives lead parties to choose the same pliable policies, those policies reflect only the interests of the better-informed members. Consequently, the parties cater to informed voters and ignore the less-well-informed voters. SIGs thus have an incentive to inform their members about the parties' policy positions.

\section{Lobbying as Information Provision}

Lobbying is the strategic presentation of information and is studied in a progression of soft-information models beginning with cheap talk, progressing to costly signaling, and continuing with educating the public in an election. The cheap talk and costly signaling models pertain to government in office, whereas informing the public pertains to choosing government. In the baseline model the SIG has a policy bias relative to the policymaker. Because of its policy bias, the SIG cannot fully communicate its information, since it has an incentive to misrepresent its information to obtain a more favorable policy. With cheap talk, the incentive to misrepresent information remains unless preferences of the lobbyist and the policymaker are closely aligned. In the Vince Crawford and Joel Sobel (1982) model, the smaller the bias the greater is the information conveyed. Although the lobbyist's information is not fully revealed, the policymaker is ex ante better off because she takes into account the strategy of the lobbyist.

Policymakers have limited time to listen to lobbyists and may use access charges to screen the lobbyists. When the subsequent lobbying is costless, it is the less biased groups that are willing to pay more for the opportunity to lobby, since once access has been obtained they can communicate more information than can a more biased SIG.

With competing but identically informed lobbyists and public messages, the information revealed depends on whether the lobbyists are on the same side or opposite sides of the policymaker. When they are on the same side, only the more moderate lobbyist can provide information, and no more information can be provided than if the more extreme lobbyist were not present.

When identically informed lobbyists are on opposite sides of the policymaker, complete revelation is still not attainable, but more information can be revealed than with a single lobbyist. Moreover, both lobbyists and the policymaker are better off ex ante. Full information revelation is not attainable because the policymaker lacks a means of disciplining the lobbyists. If the policymaker could conduct its own investigation and discover the information with some probability and had the authority to penalize the lobbyists if they misrepresented their information, on the equilibrium path the lobbyists would report their information truthfully. If their reports differed, the policymaker would conduct its own investigation and punish them with some probability. ${ }^{3}$ Similarly, if the SIGs have opposing interests, their sources of information might be expected to be different. The generality of the cheap-talk lobbying results with respect to differentiated information is unclear.

With multidimensional information and two identically informed lobbyists, one might expect full revelation of information to be more difficult to achieve, but the opposite is true. Marco Battaglini (2002) has shown that full revelation is attainable, since the interests of each lobbyist are aligned with those of the policymaker on at least one dimension. The policymaker then believes

\footnotetext{
${ }^{3}$ See David Austen-Smith and John Wright (1992).
} 
each agent on the dimension on which the agent's interests are aligned with the policymaker.

With costly signaling, more information can generally be conveyed because the cost of sending a message gives it a degree of credibility it otherwise would not have. When the cost is exogenous, i.e., it depends only on whether a message was sent, the equilibrium can distinguish only between two states, but when lobbying costs vary with the message sent, it is possible to have full revelation. Lobbying costs may also allow the SIG with a large bias to convey information. With both exogenous and endogenous costs the policymaker benefits from the lobbying, but the SIG may or may not be better off compared to tying its hands.

Grossman and Helpman bring together the lobbying models and the baseline election model by considering the SIG that can educate its members, and the public more broadly, using its information about which pliable policy is better for them. To simplify the model, both the SIG and the politicians are assumed to know the information, but the politicians are assumed to be unable to communicate their information to the public. SIG members prefer that the group leaders follow a narrow mandate focusing on the pliable policies of the parties. Early communication by SIGs directly affects the parties' choices of pliable policies, and late communication affects those policies indirectly. With late communication the parties cater to the SIGs by attempting to become the party that they will subsequently prefer to support. The authors also consider endorsements; i.e., stating a preference for one party over another, and the education of their own members. Even when the SIG communicates only with its own members, the broader public may be able to infer some of the information by observing how the parties choose their pliable policies in response to the communication. The broader public must be fully rational and sophisticated to make such an inference.

\section{Campaign Contributions}

In the third part of the book, Grossman and Helpman focus on buying influence with campaign contributions as the instrument. The basic framework is that of agency in which an interest group offers a contribution schedule to the policymaker, who chooses a policy based on its preferences for policy and contributions. The analysis begins with a single policymaker and one SIG, with the SIG making a take-it-or-leave-it offer. The equilibrium is efficient in the sense that the policy chosen maximizes a weighted average of the policy preferences of the policymaker and the SIG. The focus is on "compensating schedules" that reflect the SIG's valuation of policy changes whenever contributions are positive. ${ }^{4}$ When the policymaker maximizes a weighted sum of the SIG's interests and the public's interests, the SIG contributes the least when the weights are extreme and the most when the weights are equal. When the policymaker has strong preferences for public welfare, it is very costly to influence its policy choice, and when the policymaker has strong preferences for the SIG's interests, there is little need for influence. The authors recognize that the power in the relationship may not rest with the SIG, and also consider Nash bargaining between the two players. The basic model is applied to the allocation of public spending and to regulation and protection.

When multiple SIGs attempt to influence a single policymaker, the power in the relationship can shift to the policymaker. This is studied using a common agency model in which SIGs simultaneously choose fully compensating schedules. The resulting equilibria are jointly efficient and coalition proof in the sense that no subset of SIGs can gain from coordinated, self-enforcing actions. Applied to a trade problem, such equilibria have the property that when all

\footnotetext{
${ }^{4}$ Douglas Bernheim and Michael Whinston (1986) refer to such schedules as "truthful."
} 
members of the public are represented by some SIG, free trade results with the SIGs competing away the potential gains from political action. The power then rests with the policymaker, leaving the SIGs worse off than if they had not taken political action. This power can be restrained if the policymaker's instruments are restricted as in the case of an international trade agreement.

Many if not most government policies are chosen not by a single policymaker but by a legislature operating under some form of majority rule. Grossman and Helpman begin with vote-buying by a single SIG that also chooses the policy on which a legislature votes. Extending this model to multiple SIGs results in considerable complexity, since no pure strategy equilibrium exists. The authors thus study this setting in a model with an agenda-setter who is selected in advance of the SIG's offers. The SIG offers a contribution schedule to the agendasetter for both her policy proposal and her vote and subsequently buys the additional votes needed for passage of the proposal. The SIG may offer contributions to an agenda-setter with opposing policy preferences, and its influence is generally less than if it set the agenda. The SIG's contributions are generally smaller and the policy more favorable the stronger are the agenda-setter's preferences for contributions. With multiple SIGs the characterization of an equilibrium becomes more complicated, since the second-stage vote-buying equilibrium involves mixed strategies. Grossman and Helpman are able to obtain a complete characterization of the equilibrium, however, when the SIGs use compensating contribution schedules.

The authors conclude by bringing together campaign contributions and the baseline elections model. Contributions affect the voting of impressionable voters who do not know the positions of the parties but respond to the campaign spending of the two parties. Parties thus have a derived demand for contributions. The other voters are strategic and know the positions and policies of the parties. The SIGs focus on the pliable policies and can have two motives for contributions. One is the influence motive of inducing the parties to choose more favorable policies. The other is to elect the party with the more favorable policies. The influence motive is stronger the more the parties demand contributions, and their demand is increasing in the fraction of impressionable voters and in the effectiveness of campaign spending. The contributions can also lead the parties to choose policies other than those that maximize the welfare of the average voter. The two motives interact in the sense that the electoral motive is present only if the influence motive leads to contributions that result in different pliable policies of the parties. SIGs can contribute to both parties to influence their positions but only to their favorite to influence the election outcome. With multiple SIGs the freerider problem is present and at most one SIG contributes to each party. The electoral favorite is induced to cater more to the interest groups. If differentiable contribution schedules are used, the policies maximize a weighted sum of the SIGs' welfare and that of the strategic voters. Multiple equilibria exist and pertain to which party wins the election, but if election expectations are posited, unique policies for each party are predicted.

\section{Additional Perspectives}

In this section I identify additional perspectives on interest-group politics with a focus on richer detail, alternative perspectives on informational lobbying, and the potential significance of repetition and dynamics.

Interest groups differ considerably in their objectives, membership, and activities. One addition to the study of interest groups would be a theory of their industrial organization. Self-interested groups such as labor unions and most firms serve the interests of their members or stakeholders, 
respectively, whereas advocacy groups serve the interests of others. Activists might be distinguished from advocacy groups by their actions, which often involve confrontation in public arenas. Grossman and Helpman acknowledge these differences, but instead focus on influence activities and the institutional arenas to which those activities are directed. Knowing more about the interest groups would be useful for explaining which influence activities are used by which groups in which settings.

The authors also do not consider how SIGs are formed. In some cases this is straightforward. Common interests provide a natural incentive to participate in SIGs, and the appropriable benefits may be sufficient to overcome free-rider problems. When the appropriable benefits are small relative to the cost of participating, SIGs may provide selective benefits to members to overcome the free-rider problem. To recruit members and raise contributions, some interest groups use high-profile strategies directed toward the news media as a means of obtaining leverage in communicating with the public. In this sense the SIG may be advertising itself. The need to raise funds to support political activities is crucial for most interest groups that recruit members from among the public, which suggests that SIGs could be modeled as having a budget constraint and a revenue-generating activity.

Grossman and Helpman do not study coalitions among SIGs, but their models provide a starting point for such an analysis. On the one hand, when cheap-talk lobbying is the instrument of influence, SIGs located on the same side of the policymaker are unable to communicate more information than what the most moderate SIG can communicate. In such a case, the incentives to form a coalition may be weak. On the other hand, when contributions are the instrument of influence, SIGs with aligned policy interests may have an incentive to form a coalition. In a common agency model where all SIGs use compensating contribution schedules, the equilibrium is coalition proof, so no subset of interest groups can coordinate, without commitment or enforcement, their actions to their benefit. This suggests that in common agency settings the formation of coalitions turns on the ability to commit to coordinated actions and to enforce that commitment through direct punishments or the exclusion from future benefits. Some form of dynamics or repeated play then may be necessary to explain coalition formation. This suggests that coordination by SIGs could affect the relative power of SIGs and government in a common agency setting.

As Grossman and Helpman indicate, interest groups may direct their communication at the public to affect the election of government. In doing so, interest groups may also be attempting to motivate the public to take other influence activities. This could involve protests and demonstrations, direct communication with elected officials, and other grassroots political activity. It would be useful to unpack the preferences of government and the strategies of SIGs to accommodate such grassroots political action.

Grassroot actions can be directed not only at government but at private parties with the objective of causing them to change their policies. Activist groups, for example, campaign to force firms to improve their human rights policies and their practices, and environmental groups work to induce firms to reduce emissions below those allowed by regulations. This private politics (Baron 2002) has become a major activity of some interest groups, and the methods presented by Grossman and Helpman can be applied directly to private politics with bargaining rather than elections or legislatures resolving the conflict of interests.

Although institutional details are not a focus of the book, it is useful to ask where and how such details might matter for the study of interest-group politics. In parliamentary systems with proportional representation electoral systems, coalition governments are 
typical, and government formation involves bargaining among parties over both policy and the spoils of office. Whether coalitional considerations increase or decrease the incentives to lobby is unclear. Because coalitional considerations may matter, SIGs may alter their pre-election strategies to induce the formation of particular coalitions, in addition to influencing election outcomes.

Similarly, parliamentary systems have confidence or censure procedures. Morten Bennedsen and Sven Feldmann (2002) compared the incentives for informational lobbying in systems with and without a confidence procedure and concluded that the presence of a confidence procedure invoked by the incumbent government reduces the incentives for lobbying. ${ }^{5}$ Even though Grossman and Helpman do not carry their study of interest groups to the point of identifying variations in incentives and effectiveness due to specific institutional details, the models they present can be used to study the implications of such details.

In the lobbying models, SIGs have incentives to misrepresent their information to the government and the public. This misrepresentation may be questionable, not from a strategic perspective but from a normative perspective. If misrepresentation of information is unacceptable for an interest group, lobbying may still be possible but may take a somewhat different form and be associated with different incentives. For example, when information is hard, or verifiable, lobbying may involve selectively presenting information to government or the public. The hard information may take the form of a study conducted by the SIG, a poll of its members, or data on how many SIG members reside in a congressional district.

Mathias Dewatripont and Jean Tirole (1999) provide a model of hard information in which players advocate a position much as

\footnotetext{
5 The effect of a confidence procedure on incentives is identified in Daniel Diermeier and Timothy Feddersen (1998).
}

a lawyer represents the interests of a plaintiff or defendant in a trial. Their model uses the notion of concealment rather than misrepresentation, whereby the SIG can present information but is not required to do so. A communication strategy is thus to present favorable information and conceal unfavorable information. In some settings this type of model may be more representative of the lobbying activities of SIGs. Their model also provides a form of information aggregation in which the information presented by the SIGs can be offsetting; e.g., one SIG may make a good argument supporting a policy and another SIG may make a good argument against the policy. Or, one SIG may present information on how much one subset of constituents would benefit from a policy, and another SIG could provide information on other constituents who would be harmed by the policy. One SIG may also have an opportunity to convert soft information to hard information by investing in data, studies, and surveys, so an information generation activity may be part of the SIG's strategy set. Whether advocacy or signaling is a better predictor of lobbying remains an empirical matter.

Dewatripont and Tirole study advocacy using a screening model in which an uninformed principal offers a schedule of wages to better-informed advocates. Political parties in the United States offer different levels of access for different levels of (soft money) contributions. Legislators may also screen lobbyists to extract contributions or other forms of support from them. Grossman and Helpman offer a simple model of the allocation of scarce access, but screening models may have greater use in special interest politics than that suggested by the focus on signaling models.

Grossman and Helpman occasionally draw justification for modeling choices from repeated games, but do not formally utilize such games. This may be appropriate since repetition requires structure, but in political settings the rules of the game can be 
changed by a subset of the participants. Similarly, reputations may be harder to establish and maintain in political settings compared to markets.

More important than repetition may be dynamics. In a number of the models considered, the SIG seeks to change a policy from the status quo. Suppose that events unfold over time in a series of periods where in each period there is a shock, and the government in office then can change the status quo through the choice of a new policy. In such a case, a policy choice must take into account the current period utility and how that policy as the new status quo affects future policy choices. Similarly, in an election model an incumbent may have chosen policies in the past that limit the extent to which she can credibly commit to pliable policies in the future. In dynamic versions of the models considered, the basic incentives for influence could be considerably more complicated. Little is known about the dynamics of political choice and how interest group strategies might change in such a setting. Dynamics thus remains a rich subject for future research.

These comments are for the purpose of suggesting additional research topics or approaches to the study of special interest politics. Grossman and Helpman have provided an invaluable service to the profession by ex- tending and codifying a disparate set of models and results. Their outstanding book provides a foundation for future research on special-interest politics and more broadly for political economy.

\section{ReFERENCES}

Austen-Smith, David and John R. Wright. 1992. "Competitive Lobbying for a Legislator's Vote," Soc. Choice Welfare 9:3, pp. 229-57.

Baron, David P. 2002. "Private Politics," J. Econ. Manage. Strategy, forthcoming.

Battaglini, Marco. 2002. "Multiple Referrals and Multidimensional Cheap Talk," Econometrica 70:4, pp. 1379-401

Bennedsen, Morten and Sven Feldmann. 2002. "Lobbying and Legislative Organization: The Effect of the Vote of Confidence Procedure," Bus. Politics, forthcoming.

Bernheim, B. Douglas and Michael D. Whinston. 1986. "Menu Auctions, Resource Allocation, and Economic Influence," Quart. J. Econ. 101:1, pp. $1-31$.

Crawford, Vincent P. and Joel Sobel. 1982. "Strategic Information Transmission,” Econometrica 50:6, pp. 1431-51.

Dewatripont, Mathias and Jean Tirole. 1999. "Advocates," J. Polit. Econ. 107:1, pp. 1-39.

Diermeier, Daniel and Timothy J. Feddersen. 1998. "Cohesion in Legislatures and the Vote of Confidence Procedure," Amer. Polit. Sci. Rev. 92:3, pp. 611-21.

Grossman, Gene M. and Elhanan Helpman. 1994. "Protection for Sale," Amer. Econ. Rev. 84:4, pp. 833-50.

Riker, H. William and Peter C. Ordeshook. 1968. "A Theory of the Calculus of Voting," Amer. Polit. Sci. Rev. 62:1, pp. 25-42. 